\title{
Purification and Properties of an Enzyme Involved in the ATP-de- pendent Activation of the Methanol:2-Mercaptoethanesulfonic Acid Methyltransferase Reaction in Methanosarcina barkeri*
}

(Received for publication, December 29, 1995, and in revised form, June 7, 1996)

\author{
Piet J. H. Daas, Roel W. Wassenaar, Pierre Willemsen, René J. Theunissen, Jan T. Keltjensł, \\ Chris van der Drift, and Godfried D. Vogels \\ From the Department of Microbiology, Faculty of Science, University of Nijmegen, Toernooiveld, \\ NL-6525 ED Nijmegen, The Netherlands
}

\begin{abstract}
In Methanosarcina barkeri the transfer of the methyl group from methanol to 2-mercaptoethanesulfonic acid is catalyzed by the concerted action of two methyltransferases. The first one is the corrinoid-containing methanol:5-hydroxybenzimidazolylcobamide methyltransferase $\left(M_{1}\right)$, which binds the methyl group of methanol to its corrinoid prosthetic group. $\mathrm{MT}_{1}$ is only catalytically active when the cobalt atom of the corrinoid is present in the highly reduced $C o(I)$ state. In the course of its purification and even during catalysis, $\mathbf{M T}_{1}$ becomes oxidatively inactivated. The enzyme, however, may be reductively reactivated by a suitable reducing system (hydrogen and hydrogenase), ATP, and an enzyme called methyltransferase activation protein (MAP). In order to elucidate its role in the reactivation process, MAP was purified to apparent homogeneity. The protein had an $M_{r}=60,000$. Preincubation of the enzymic components involved with 8-azido-ATP or with ATP demonstrated MAP to be the primary site of action of ATP. In agreement herewith, the protein was autophosphorylated by $\left[\gamma_{-}{ }^{32} \mathrm{P}\right] \mathrm{ATP}$ in a $1: 1$ stoichiometry. Phosphorylated MAP substituted for ATP in the activation of $\mathrm{MT}_{1}$, and the addition of increasing amounts of MAP phosphate resulted in a corresponding increase of active $\mathrm{MT}_{1}$. However, in the presence of limiting amounts of MAP, maximal activation of $\mathrm{MT}_{1}$ could be achieved during a lag phase provided ATP was present, indicating that MAP acts as a catalyst. This paper is the first to report on the presence, isolation, and function of a phosphorylated protein in a methanogenic archaeon.
\end{abstract}

Corrinoid $\left(\mathrm{B}_{12}\right)$-containing enzymes catalyze two distinct classes of reactions, notably $\mathrm{C}-\mathrm{C}$ rearrangements and methyl group transfers. The typical example of the latter enzymes is methyltetrahydrofolate:homocysteine methyltransferase (methionine synthase) (1). In recent years evidence has been accumulating that corrinoid proteins play a central role in a variety of anaerobic conversion reactions like acetate biosynthesis and degradation, biodegradation of methoxylated aromates, methylated amines and sulfur compounds, and methylated heavy metals (2-4). The conversions are brought about by diverse groups of obligate anaerobic micro-organisms, including sulfate reducers, homoacetogens and obligate proton reducers, and methanogenic archaea $(3,4)$. Methylotrophic methanogens spe-

* The costs of publication of this article were defrayed in part by the payment of page charges. This article must therefore be hereby marked "advertisement" in accordance with 18 U.S.C. Section 1734 solely to indicate this fact.

$\ddagger$ To whom correspondence should be addressed. Tel.: 31-24-3653437; Fax: 31-24-3553450; E-mail: jankel@sci.kun.nl.

This is an open access article under the CC BY license. cialized in methane formation from methylated one-carbon compounds are particularly rich in corrinoid proteins (2).

Being nature's most powerful nucleophile, the corrinoid prosthetic group is elegantly designed to act in methyl group displacement (4). The coenzyme, however, suffers from the intrinsic disadvantage that this function is only displayed when the central cobalt is present in the superreduced $\mathrm{Co}(\mathrm{I})$ reduction state and even the slightest oxidative in vivo and in vitro conditions cause an oxidation of the cobalt atom and concomitant enzyme inactivation. For this reason, organisms that employ corrinoid proteins in their metabolism contain certain reactivation systems, in which ATP is somehow used to push the unfavorable $\mathrm{Co}$ (II) to $\mathrm{Co}$ (I) reduction across a thermodynamic barrier $(3,5)$. The mechanism of action of ATP is best understood in the methionine synthetase system, in which ATP functions as the substrate in the synthesis of the potent methylating trapping agent, $S$-adenosylmethionine (5). The way ATP is operative in the reductive activation of other methyltransferases present in the obligately anaerobic micro-organisms mentioned above is, however, unknown. In order to clarify the role of ATP, we have now investigated the methanol:2mercaptoethanesulfonic acid (coenzyme M, HS-CoM) ${ }^{1}$ methyltransferase system from the methylotrophic methanogen Methanosarcina barkeri.

Methanol:HS-CoM methyltransferase catalyzes the synthesis of methyl-coenzyme $\mathrm{M}\left(\mathrm{CH}_{3}-\mathrm{S}-\mathrm{CoM}\right)$, which is the substrate of the methane-forming reaction (2). The methyltransferase is a multicomponent system composed of two methyltransferases, methanol:5-hydroxybenzimidazolylcobamide methyltransferase $\left(\mathrm{MT}_{1}\right)$ and Co-methyl-5-hydroxybenzimidazolylcobamide:HS-CoM methyltransferase ( $\left.\mathrm{MT}_{2}\right)$. $\mathrm{MT}_{1}$ accepts the methyl group of methanol and binds it to the oxidation-sensitive 5-hydroxybenzimidazolyl cob(I)amide prosthetic group. $\mathrm{MT}_{2}$ subsequently transfers the methyl group to HS-CoM $(6,7)$. Since $\mathrm{MT}_{1}$ can only be isolated in an oxidized state (7), the presence of a suitable reducing system (hydrogen and hydrogenase) in the assays is a prerequisite for the recovery of $\mathrm{MT}_{1}$ activity (8, 9 ). The electron carrier ferredoxin enhances the activation rate, but the compound is not required per se (10). Activation is strictly dependent on the presence of a catalytic amount of ATP

\footnotetext{
${ }^{1}$ The abbreviations used are: HS-CoM (coenzyme M), 2-mercaptoethanesulfonic acid; $\mathrm{CH}_{3}$-S-CoM (methyl-coenzyme M), 2-(methylthio)ethanesulfonic acid; $\mathrm{MT}_{1}$, methanol:5-hydroxybenzimidazolylcobamide methyltransferase; $\mathrm{MT}_{2}$, Co-methyl-5-hydroxybenzimidazolylcobamide:HS-CoM methyltransferase; MAP, methyltransferase activation protein; CHAPS, 3-[(3-cholamidopropyl)-dimethylammonio]-1-propanesulfonate; PAGE, polyacrylamide gel electrophoresis; IEF, isoelectric focusing; TES, $N$-tris-(hydroxymethyl)-methyl-2-aminoethanesulfonic acid; $\mathrm{kPa}$, kilopascal(s); AMP-PNP, adenylylamidodiphosphate; AMPPCP, adenylyl-( $\beta, \gamma$-methylene)diphosphonate.
} 
and of an enzymic component(s) present in crude cell extracts termed methyltransferase activation protein (MAP) (10). In this paper we describe the purification of MAP and show it to be the primary site of action of ATP. Evidence will be presented that MAP is autophosphorylated by ATP suggesting that phosphorylated MAP is the effector in $\mathrm{MT}_{1}$ activation.

\section{EXPERIMENTAL PROCEDURES}

Cell Material-Mass culture of cells of M. barkeri strain MS (DSM 800 ) and the anaerobic preparation of cell extract proceeded as described previously $(10,11)$.

Enzyme Assays-Unless stated otherwise, incubation mixtures were prepared in an anaerobic glove box. Reactions were performed in 10-ml serum vials closed with butyl rubber stoppers and aluminum crimp seals.

MAP activity was determined by the ability to restore the methanoldependent $\mathrm{HS}-\mathrm{CoM}$ conversion to $\mathrm{CH}_{3}-\mathrm{S}-\mathrm{CoM}$ when added to a reaction mixture containing $\mathrm{MT}_{1}, \mathrm{MT}_{2} /$ hydrogenase, and ferredoxin. The enzymes were obtained by DEAE-Sepharose-Cl-6B chromatography of cell extract of $M$. barkeri (10). A typical reaction mixture (final volume, 100 $\mu$ l) contained $50 \mathrm{~mm} \mathrm{TES} / \mathrm{K}^{+}$buffer ( $\mathrm{pH} 7.0$ ), $24 \mathrm{~mm} \mathrm{MgCl}_{2}, 10 \mathrm{~mm}$ methanol, $10 \mathrm{~mm}$ HS-CoM, $2 \mathrm{~mm}$ ATP, $1 \mathrm{~mm}$ 2-bromoethanesulfonic acid (to inhibit enzymic reduction of $\mathrm{CH}_{3}$-S-CoM in crude systems), 20 $\mu \mathrm{l}$ of $\mathrm{MT}_{2} /$ hydrogenase fraction $\left(2.47 \mathrm{mg}\right.$ of protein $\mathrm{ml}^{-1} ; 1.42 \mu \mathrm{mol}$ of HS-CoM converted $\min ^{-1} \mathrm{mg}$ of protein ${ }^{-1} ; 0.10 \mu \mathrm{mol}$ of benzylviologen reduced $\min ^{-1} \mathrm{mg}$ of protein ${ }^{-1} ; 0.02 \mu \mathrm{mol}$ of coenzyme $\mathrm{F}_{420}$ reduced $\min ^{-1} \mathrm{mg}$ of protein ${ }^{-1}$ ), $12.5 \mu \mathrm{l}$ of $\mathrm{MT}_{1}$ fraction (3.43 mg of protein $\mathrm{ml}^{-1}$; $0.88 \mu \mathrm{mol}$ of HS-CoM converted $\min ^{-1} \mathrm{mg}$ of protein ${ }^{-1}$ ), $5 \mu \mathrm{l}$ of ferredoxin fraction $\left(0.36 \mathrm{mg}\right.$ of protein $\mathrm{ml}^{-1} ; 0.34 \mu \mathrm{mol}$ of dithiodiethanesulfonic acid reduced $\mathrm{min}^{-1} \mathrm{mg}$ of protein ${ }^{-1}$ ), and a 40- $\mu \mathrm{l}$ column fraction as a source of MAP. After gassing with $50 \% \mathrm{H}_{2}, 50 \% \mathrm{~N}_{2}(100 \mathrm{kPa})$, the vials were kept on ice. Reactions were started by placing the vials at $37^{\circ} \mathrm{C}$. After appropriate incubation periods, usually $0,15,30,45$, and $60 \mathrm{~min}$, reactions were stopped by placing the vials on ice. Hereafter, the amount of HS-CoM present in the incubation mixtures was measured with Ellman reagent (see below) and activity of methyl group transfer from methanol to HS-CoM was calculated from the rate of HS-CoM conversion (10).

Since MAP only affects the lagging of the methyltransferase reaction, rather than the rate of HS-CoM conversion, a nonlinear relation exists between the amount of MAP present in the assays and the amount of HS-CoM converted at a certain point of time (10). In order to quantify MAP activity, an arbitrary unit was defined to enable a purification scheme to be drawn up. One arbitrary unit (AU) was defined as the amount of MAP present in $5 \mu \mathrm{l}$ of cell extract $(0.13 \mathrm{mg}$ of protein). The latter value was chosen such that HS-CoM conversion by the extract alone was negligible, while when added to the standard assay the reaction proceeded without an appreciable lag period; under these conditions, $0.38 \mu \mathrm{mol}$ of HS-CoM was converted in $45 \mathrm{~min}$. To determine the MAP activity of a purified fraction, a series of standard reaction mixtures was prepared with decreasing amounts of the fraction. Following an incubation of $45 \mathrm{~min}$, the particular test mixture, which just showed a HS-CoM conversion equal to $5 \mu \mathrm{l}$ of cell extract by definition, contained 1 AU of MAP activity.

The enzymatic activities of $\mathrm{MT}_{1}$ and $\mathrm{MT}_{2}$ were determined by measuring the rate of HS-CoM decrease in the presence of a saturating amount of MAP (routinely $25 \mu \mathrm{l}$ of MAP fraction obtained after DEAESepharose chromatography of cell extract) (10). The methyltransferase activities obtained were linearly dependent on the amount of $\mathrm{MT}_{1}$ or $\mathrm{MT}_{2} /$ hydrogenase fraction added. Hydrogenase and ferredoxin activity were determined as described before $(8,10)$.

ATP conversion measured by the luminometric assay (see below) was followed in 100- $\mu$ l reaction mixtures that contained $50 \mathrm{mM} \mathrm{TES} / \mathrm{K}^{+}$ buffer (pH 7.0), $20 \mathrm{mM} \mathrm{MgCl}_{2}, 0.125 \mu \mathrm{M} \mathrm{ATP}$, and $40 \mu \mathrm{l}$ of MAP fraction. Anoxic preparation of the reaction mixtures in 10-ml serum vials and subsequent incubation proceeded as described for the MAP assay described above. After incubation periods of 0,30 , and $60 \mathrm{~min}$, reactions were stopped by placing the vials on ice and samples were drawn for analysis. Similar procedures were used to assay the MAP-dependent conversion of $\left[8-{ }^{14} \mathrm{C}\right] \mathrm{ATP}$ into $\left[8-{ }^{14} \mathrm{C}\right] \mathrm{ADP}$ and the phosphorylation of MAP by $\left[\gamma_{-}{ }^{32} \mathrm{P}\right] \mathrm{ATP}$, except that the reaction mixtures contained $2 \mu \mathrm{M}$ $\left[8{ }^{-14} \mathrm{C}\right]$ ATP $\left(1.89 \mathrm{TBq} \mathrm{mol}^{-1}\right)$ and $2 \mu \mathrm{M}\left[\gamma^{3}{ }^{32} \mathrm{P}\right] \mathrm{ATP}\left(8350 \mathrm{TBq} \mathrm{mol}{ }^{-1}\right)$, respectively. Incubations took place for $0,15,60$, and $120 \mathrm{~min}$ at $37^{\circ} \mathrm{C}$ under $50 \% \mathrm{H}_{2}, 50 \% \mathrm{~N}_{2}(100 \mathrm{kPa})$.

Purification of MAP-Because MAP is an oxygen-labile protein (10), all procedures were performed at room temperature in an anaerobic glove box $\left(97.5 \% \mathrm{~N}_{2}, 2.5 \% \mathrm{H}_{2}\right)$. The purification procedure was initiated by applying $10 \mathrm{ml}$ of cell extract to a DEAE-Sepharose Cl-6B column and separating MAP from the other proteins involved in the methanol: HS-CoM methyltransferase reaction as described before (10). Fractions containing MAP activity eluting between 0.25 and $0.34 \mathrm{M} \mathrm{NH}_{4} \mathrm{Cl}$ were combined and concentrated to $6 \mathrm{ml}$ by ultrafiltration using a Amicon YM-10 membrane. To this concentrated fraction, $6 \mathrm{ml}$ of $50 \mathrm{mM} \mathrm{TES} / \mathrm{K}^{+}$ buffer ( $\mathrm{pH} 7.0$ ) containing $1 \mathrm{~mm}$ dithiothreitol and $4 \mathrm{M} \mathrm{NH}_{4} \mathrm{Cl}$ was added. The sample was placed on a column packed with phenyl-Sepharose CL-4B $(6.5$ by $1.5 \mathrm{~cm})$ and equilibrated in $50 \mathrm{mM} \mathrm{TES} / \mathrm{K}^{+}$buffer (pH 7.0) containing $2 \mathrm{M} \mathrm{NH}_{4} \mathrm{Cl}, 15 \mathrm{mM} \mathrm{MgCl}_{2}$, and $1 \mathrm{mM}$ dithiothreitol. After application of the sample, the column was washed with $70 \mathrm{ml}$ of equilibration buffer followed by a single-step elution of bound protein with $50 \mathrm{ml}$ of $50 \mathrm{~mm}$ TES/K ${ }^{+}$buffer $(\mathrm{pH} 7.0)$ containing $15 \mathrm{mM} \mathrm{MgCl}_{2}$, $1 \mathrm{~mm}$ dithiothreitol, and $10 \%$ ethylene glycol. The eluate was monitored at $280 \mathrm{~nm}$, and $2.5-\mathrm{ml}$ fractions were collected at a flow rate of $3 \mathrm{ml}$ $\mathrm{min}^{-1}$. MAP activity was eluted at the $10 \%$ ethylene glycol step. Active fractions were combined and concentrated by ultrafiltration to a final volume of $1 \mathrm{ml}$. MAP was further purified using a Perkin-Elmer fast protein liquid chromatography system placed inside the glove box and equipped with a TSK DEAE-5-PW column $(7.5 \mathrm{~cm}$ by $0.75 \mathrm{~cm})$. The column was equilibrated in $50 \mathrm{mM} \mathrm{TES} / \mathrm{K}^{+}$buffer $(\mathrm{pH} 7.0)$ containing 15 $\mathrm{mM} \mathrm{MgCl}_{2}, 1 \mathrm{~mm}$ dithiothreitol, $10 \%$ ethylene glycol, and $0.5 \mathrm{~mm}$ CHAPS. After application of the sample, separation took place by a $7-\mathrm{ml}$ wash with the equilibration buffer followed by a $100-\mathrm{ml}$ linear gradient of 0 to $0.5 \mathrm{M} \mathrm{NH}_{4} \mathrm{Cl}$ in the buffer. Fractions of $0.9 \mathrm{ml}$ were collected at a flow rate of $0.45 \mathrm{ml} \mathrm{min}{ }^{-1}$. MAP activity was recovered in a peak that was eluted at $0.16 \mathrm{M} \mathrm{NH}_{4} \mathrm{Cl}$. Fractions containing MAP were combined and concentrated by Amicon YM-10 ultrafiltration to a volume of $1 \mathrm{ml}$. Hereafter, MAP was brought to homogeneity on a TSK-Gel HA-1000 column $(7.5$ by $0.75 \mathrm{~cm})$ equilibrated in $50 \mathrm{~mm}$ TES/K $\mathrm{K}^{+}$buffer $(\mathrm{pH} 7.0)$ containing $1 \mathrm{~mm}$ dithiothreitol, $0.5 \mathrm{~mm}$ CHAPS, and $10 \%$ ethylene glycol. The sample was applied to the hydroxylapatite column and the column was washed with $15 \mathrm{ml}$ of the equilibration buffer. Bound protein was eluted by a $50-\mathrm{ml}$ simultaneous linear gradient of $50-0 \mathrm{mM}$ TES/ $\mathrm{K}^{+}$buffer $(\mathrm{pH} 7.0$ ) and 0-300 $\mathrm{mm}$ ammonium phosphate buffer (pH 7.0); both buffers contained $1 \mathrm{~mm}$ dithiothreitol, 0.5 mM CHAPS, and $10 \%$ ethylene glycol. Fractions of $0.9 \mathrm{ml}$ were collected at a flow rate of $0.45 \mathrm{ml} \mathrm{min}{ }^{-1}$. MAP was present in a small symmetrical peak that was eluted at $145 \mathrm{~mm}$ ammonium phosphate and $26 \mathrm{~mm}$ TES/K ${ }^{+}$. The enzyme pool was concentrated and desalted on an Ultrafree-MC filter unit (nominal molecular weight cutoff of 10,000 ) by washing with $50 \mathrm{mM}$ $\mathrm{TES} / \mathrm{K}^{+}$buffer ( $\mathrm{pH} 7.0$ ) containing $1 \mathrm{~mm}$ dithiothreitol and $10 \%$ ethylene glycol.

Photoaffinity Labeling-Reaction mixtures containing the protein fraction $(560 \mu \mathrm{l})$ and $2 \mathrm{~mm} 8$-azido-ATP were prepared inside the anaerobic glove box in 1-ml quartz cuvettes. The cuvettes were closed with rubber stoppers, taken out of the box, and gassed with nitrogen $(130 \mathrm{kPa})$. The reaction mixtures were illuminated for $1 \mathrm{~h}$ at $4{ }^{\circ} \mathrm{C}$ by a 6 -watt 5C UV light (Philips, Eindhoven, The Netherlands) positioned at a distance of $6 \mathrm{~cm}$. Hereafter, the mixtures were thoroughly washed with $50 \mathrm{~mm}$ TES$/ \mathrm{K}^{+}$buffer ( $\mathrm{pH} 7.0$ ) containing $1 \mathrm{~mm}$ dithiothreitol and $10 \%$ ethylene glycol inside the anaerobic glove box on Ultrafree-MC filter units to remove noncovalently bound nucleotides. Activity of the proteins was measured as described above. The cuvettes and vials of the controls containing the unexposed protein fractions were subject to the same procedure, except that they were wrapped in aluminum foil.

Preincubations with ATP-Inside the glove box protein to be tested (either washed and concentrated MAP obtained from the DEAE-Sepharose Cl-6B column chromatography step or the combined $\mathrm{MT}_{1}$ and $\mathrm{MT}_{2}$ /hydrogenase fractions) was incubated with $2 \mathrm{~mm}$ ATP and $15 \mathrm{~mm}$ $\mathrm{MgCl}_{2}$ at ambient temperature for $10 \mathrm{~min}$. Hereafter, glucose $(4 \mathrm{mM})$, hexokinase (22 units), and myokinase (15 units) were added to remove excess ATP and the ADP formed. Following another 10-min incubation, an amount of the preincubated protein was mixed with the other components (except ATP) of the methanol:HS-CoM methyltransfer (MAP) asay and the HS-CoM conversion was followed in the further absence of ATP as described above.

Analytical Procedures-Native polyacrylamide gel electrophoresis (PAGE), denaturing SDS-PAGE, and isoelectric focusing (IEF) were performed with prefabricated minigels using PhastSystem equipment (Pharmacia, Uppsala, Sweden). The gels were stained with Coomassie Brilliant Blue R-250. The molecular mass of denaturated protein was determined by electrophoresis on a 10-15\% gradient minigel with SDSbuffer strips. Prior to application, the protein was stored at room temperature $\left(22^{\circ} \mathrm{C}\right)$ for $1 \mathrm{~h}$ in $5 \mathrm{~mm}$ Tris $/ \mathrm{Cl}^{-}(\mathrm{pH} 8.8)$ that contained $1 \%$ SDS, $4 \% \beta$-mercaptoethanol, and $10 \%$ glycerol. Protein markers (BioRad) were the following (Da): $\alpha$-lactalbumin $(14,400)$, soybean trypsin inhibitor $(21,500)$, bovine carbonic anhydrase $(31,000)$, hen egg white 
TABLE I

Purification of methyltransferase activation protein from $M$. barkeri

The purification procedure started from $10 \mathrm{ml}$ of cell extract. Enzyme assays were performed as described under "Experimental Procedures." The activity is expressed in arbitrary units (AU). One AU is defined as the amount of MAP activity present in $5 \mu \mathrm{l}$ of cell extract as described under "Experimental Procedures."

\begin{tabular}{|c|c|c|c|c|c|}
\hline Step & Total protein & Total activity & Specific activity & Factor & Recovery \\
\hline & $m g$ & $A U$ & $A U / m g$ & -fold & $\%$ \\
\hline Cell extract & 264 & 2000 & 7.6 & 1.0 & 100 \\
\hline DEAE-Sepharose & 26 & 363 & 14 & 1.8 & 18 \\
\hline Phenyl-Sepharose & 5.9 & 110 & 19 & 2.5 & 5.5 \\
\hline TSK DEAE & 1.6 & 45 & 28 & 3.7 & 2.3 \\
\hline Hydroxylapatite & 0.04 & 24 & 600 & 79 & 1.2 \\
\hline
\end{tabular}

lysozyme (45,000), bovine serum albumin $(66,200)$, and rabbit muscle phosphorylase $b(97,400)$. Native PAGE was performed on a $8-25 \%$ gradient minigel using the following markers (Sigma): $\alpha$-lactalbumin $(14,200)$, chicken egg albumin $(45,000)$, the monomer $(66,000)$ and dimer $(132,000)$ of bovine serum albumin, and the trimer $(272,000)$ and hexamer $(545,000)$ of jack bean urease. Isoelectric focusing was performed with a pH 3-9 IEF gel using the pI 4.6-9.6 IEF standard proteins from Bio-Rad. The molecular mass of the native protein was estimated by gel filtration on Superose-6 HR calibrated with cyanocobalamin $(1,355)$ and the following high molecular mass markers (Da) obtained from Sigma: carbonic anhydrase $(29,000)$, bovine serum albu$\min (66,000)$, apoferritin $(443,000)$; blue dextran was added for determination of the void volume. The column ( 30 by $1 \mathrm{~cm}$ ) was equilibrated and eluted with $50 \mathrm{~mm} \mathrm{TES} / \mathrm{K}^{+}$buffer ( $\mathrm{pH} 7.0$ ) containing $15 \mathrm{~mm} \mathrm{MgCl}$, $1 \mathrm{~mm}$ dithiothreitol, $10 \%$ ethylene glycol, $150 \mathrm{mM} \mathrm{NH}_{4} \mathrm{Cl}$, and $0.5 \mathrm{~mm}$ CHAPS. Fractions of $0.36 \mathrm{ml}$ were collected at a flow rate of $0.18 \mathrm{ml}$ $\min ^{-1}$.

ATP concentrations were measured on a LKB-Wallac 1250 luminometer using the ATP bioluminescence CLS reagent from Boehringer (Mannheim, Germany (FRG)). A 25- $\mu$ l sample of the reaction mixture was mixed with $25 \mu \mathrm{l}$ of ATP bioluminescence reagent and $450 \mu \mathrm{l}$ of 40 mM HEPES buffer ( $\mathrm{pH}$ 7.75) containing 4 mM EDTA, and immediately placed in the luminometer. The conversion of $\left[8-{ }^{14} \mathrm{C}\right] \mathrm{ATP}$ into $\left[8-{ }^{14} \mathrm{C}\right] \mathrm{ADP}$ was followed by adding $400 \mu \mathrm{l}$ of $96 \%$ ethanol to the $100-\mu \mathrm{l}$ reaction mixture at $4{ }^{\circ} \mathrm{C}$; controls showed that, unlike part of the ATP, ADP did not precipitate under the experimental conditions. Protein and the precipitated part of $\left[8-{ }^{14} \mathrm{C}\right] \mathrm{ATP}$ was subsequently removed by centrifugation for $15 \mathrm{~min}$ at $16,000 \times \mathrm{g}$ (Eppendorf). Aliquots $(40 \mu \mathrm{l})$ of the supernatant were spotted on polyethyleneimine-cellulose $\mathrm{F}$ thin-layer chromatography (TLC) plates (0.1 mm; Merck AG, Darmstadt, FRG) that were developed with $2 \mathrm{M}$ formic acid containing $0.5 \mathrm{M} \mathrm{LiCl}$ (12). $R_{F}$ values of ATP, ADP, and AMP were $0.12,0.68$, and 0.91 , respectively. Radioactive spots were located by exposing the TLC plates to Kodak XAR-5 x-ray film for 8 days at $-80^{\circ} \mathrm{C}$. Hereafter, radioactive spots showing the $R_{F}$ of ADP were cut out, cellulose was scratched off, suspended in $1 \mathrm{ml}$ of water, mixed with $9 \mathrm{ml}$ of Lumagel scintillation fluid (Lumac, Schaesberg, The Netherlands) and counted for activity. By spotting known amounts of $\left[8-^{14} \mathrm{C}\right] \mathrm{ATP}$ to a polyethyleneiminecellulose TLC plate, cutting out and scratching off the active spots, and counting the radioactivity, a calibration curve was prepared which enabled the quantification of $\left[8-\mathrm{C}^{14}\right] \mathrm{ADP}$. In order to quantify the protein phosphorylation by $\left[\gamma^{32} \mathrm{P}\right]$, reaction mixtures were extensively washed with $50 \mathrm{~mm} \mathrm{TES} / \mathrm{K}^{+}$buffer $(\mathrm{pH} 7.0)$ on Ultrafree-MC filter units. Hereafter, the filters were taken to dryness and counted for radioactivity. Alternatively, labeled MAP was precipitated together with bovine serum albumin (final concentration: $1 \mathrm{mg} / \mathrm{ml}$ ) by adding $100 \mu \mathrm{l}$ of ice-cold $40 \%$ trichloroacetic acid to the reaction mixtures (100 $\mu \mathrm{l})$. After standing for $5 \mathrm{~min}$ at $4{ }^{\circ} \mathrm{C}$, proteins were pelleted by centrifugation $\left(5 \mathrm{~min}\right.$ at $\left.4{ }^{\circ} \mathrm{C}\right)$ in a minicentrifuge. Hereafter, the precipitate was resuspended in $400 \mu \mathrm{l}$ of ice-cold $20 \%$ trichloroacetic acid and centrifugated as before. The washing step was repeated four times; preliminary experiments showed that the supernatant now was free of label and that radioactivity of the protein fraction had become constant. The amount of protein-bound $\left[\gamma_{-}{ }^{32} \mathrm{P}\right]$ was calculated by comparison to a calibration curve prepared from $\left[\gamma^{-32} \mathrm{P}\right]$ ATP. PAGE gels that were run to demonstrate the binding of ${ }^{32} \mathrm{P}_{\mathrm{i}}$ with protein were dried, and the front was cut off to remove excess unreacted $\left[\gamma_{-}{ }^{32} \mathrm{P}\right] \mathrm{ATP}$. Radioactivity was located by autoradiography for $6 \mathrm{~h}$ using the Kodak XAR-5 x-ray film.

Protein was determined with the Bio-Rad protein reagent with bovine serum albumin as a standard. UV-visible light absorption spectra were recorded on a Hitachi U-3200 spectrophotometer. HS-CoM was determined by the method of Ellman (13). Samples of $25 \mu \mathrm{l}$ were mixed

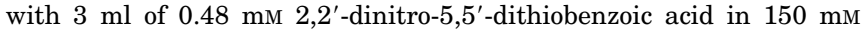

Tris/ $\mathrm{Cl}^{-}$buffer ( $\mathrm{pH} 8.0$ ) and measured immediately at $412 \mathrm{~nm}$. The acid stability of the phosphate linkage of the ${ }^{32} \mathrm{P}$-labeled protein was determined as described by Martensen (14).

Materials-All chemicals used were of analytical grade. HS-CoM, 2-bromoethanesulfonic acid, HEPES, TES, and 8-azido-ATP were purchased from Sigma. Dithiothreitol was from Serva Feinbiochemica (Heidelberg, FRG). LiCl was obtained from Merck AG (Darmstadt, FRG). ATP, hexokinase, myokinase, and CHAPS were purchased from Boehringer (Mannheim, FRG). DEAE-Sepharose Cl-6B, phenyl-Sepharose CL-4B, and Superose- 6 HR were from Pharmacia LKB Biotechnology AB (Uppsala, Sweden). TSK DEAE-5-PW and TSK-Gel HA-1000 columns were obtained from TosoHaas (Stuttgart, FRG). Ultrafree-MC filter units were acquired from Millipore (Etten-Leur, The Netherlands). $\left[8-{ }^{14} \mathrm{C}\right]$ ATP $\left(1.89 \mathrm{TBq} \mathrm{mol}^{-1}\right)$ came from Amersham (Buckinghamshire, UK). $\left[\gamma_{-}{ }^{32} \mathrm{P}\right]$ ATP $\left(8350 \mathrm{TBq} \mathrm{mol}^{-1}\right)$ was obtained from ICN Biomedicals (Zoetermeer, The Netherlands). Gasses were supplied by Hoek-Loos (Schiedam, The Netherlands). To remove traces of oxygen, $\mathrm{H}_{2}$-containing gasses were passed over a BASF RO-20 catalyst at room temperature and nitrogen was passed over a prereduced BASF R3-11 catalyst at $150{ }^{\circ} \mathrm{C}$. The catalysts were a gift of BASF Aktiengesellschaft (Ludwigshafen, FRG).

\section{RESULTS}

Purification of MAP - Methyltransferase Activation Protein was purified to homogeneity from cell extracts of $M$. barkeri strain MS as summarized in Table I. After this stage only one band could be detected after native and SDS-PAGE (Fig. 1). The purification of MAP proved to be quite difficult. First of all, the enzyme was very oxygen-labile (10); as a consequence, purification had to be performed under carefully controlled anaerobic conditions. Addition of $10 \%$ ethylene glycol, which had a preservative action during storage at $4{ }^{\circ} \mathrm{C}$ or $-20^{\circ} \mathrm{C}$ of crude preparations (10), was less effective in this respect with the more purified proteins. Another factor that contributed to the low overall yield was that MAP was eluted from the columns as a very broad band. Occasionally, even two or three activity peaks were found. Elution as a broad band was also observed, when the TSK-DEAE and hydroxylapatite steps were performed in the absence of CHAPS. Addition of the zwitterionic detergent to the buffers, however, resulted in enhanced resolution, and only one activity peak was recovered. The peak broadening and the distribution of activity over several peaks could be due to an interaction with other proteins. After the first step, only $18 \%$ of MAP activity was recovered. Although addition of ethylene glycol and CHAPS in the final purification steps did have a positive effect on recovery, the final yield was still only $1.2 \%$.

Purified MAP showed an apparent molecular mass of 59,000 Da upon nondenaturing 8-25\% PAGE. This value closely agreed the $M_{\mathrm{r}}=60,000$ obtained by gel filtration chromatography on Superose-6 (Fig. 2B). During SDS sample preparation, MAP exhibited an unusual temperature instability. After incubation of MAP at elevated temperatures (1-2 min at $100{ }^{\circ} \mathrm{C}$, or $5 \mathrm{~min}$ at $80^{\circ} \mathrm{C}$ ) in SDS sample buffer and subsequent electrophoresis, a band showing an $M_{\mathrm{r}}=60,000$ and a very broad and diffuse band around $30 \mathrm{kDa}$ was stained on the gel. However, when MAP was kept in SDS sample buffer for $1 \mathrm{~h}$ at 
ambient or lower temperature, a single band was detected with $M_{\mathrm{r}}=60,000$ (Figs. 1 and $2 A$ ). Isoelectric focusing indicated a pI of 5.0 for the protein.

Concentrated active MAP preparations were colorless, and in the UV-visible light spectrum no absorbing bands were found above $300 \mathrm{~nm}$. Identical spectra were recorded under aerobic and anaerobic conditions. This indicated that MAP does not contain a specific (redox-sensitive) chromophoric group. MAP was not inactivated after pretreatment with 2 mM EDTA, suggesting that bivalent cations were not required for protein stabilization.

Interaction with 8-Azido-ATP-Methyl group transfer of methanol to HS-CoM is dependent on $\operatorname{ATP}(9,10)$. Previously it had been described that the compound could be substituted to variable extents by GTP, CTP, UTP, but not ITP and TTP (9). We now found that 8-azido-ATP was active as well, contrary to dATP, 2',3'-dialdehyde-ATP, and non-hydrolyzable ATP analogues such as AMP-PNP and AMP-PCP. The effect of 8-azidoATP on the methyltransferase reaction was studied in some detail. The nucleotide is a commonly used reactive ATP analogue, which can react with all amino acid residues after weak UV illumination and thereby covalently attaches to ATP-binding sites (15). Experiments performed with partly purified MAP obtained from the DEAE-Sepharose column indicated that 8-azido-ATP could substitute to a significant degree for ATP in the standard assay: if protected from light, the reaction in the presence of $2 \mathrm{~mm} 8$-azido-ATP proceeded without a lag

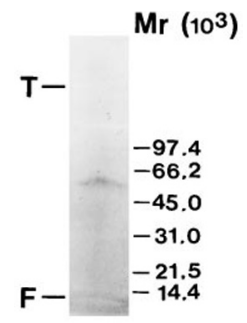

FIG. 1. SDS-polyacrylamide gel electrophoresis of purified methyltransferase activation protein. The protein was prepared for SDS-PAGE as described under "Experimental Procedures." A 4- $\mu$ l sample (2.6 $\mu \mathrm{g}$ protein) was applied to a $10-15 \%$ gradient Phastgel and stained with Coomassie Brilliant Blue. The numbers at the right side refer to the molecular masses $(\mathrm{kDa})$ of the protein markers. $T$, top; $F$, front.

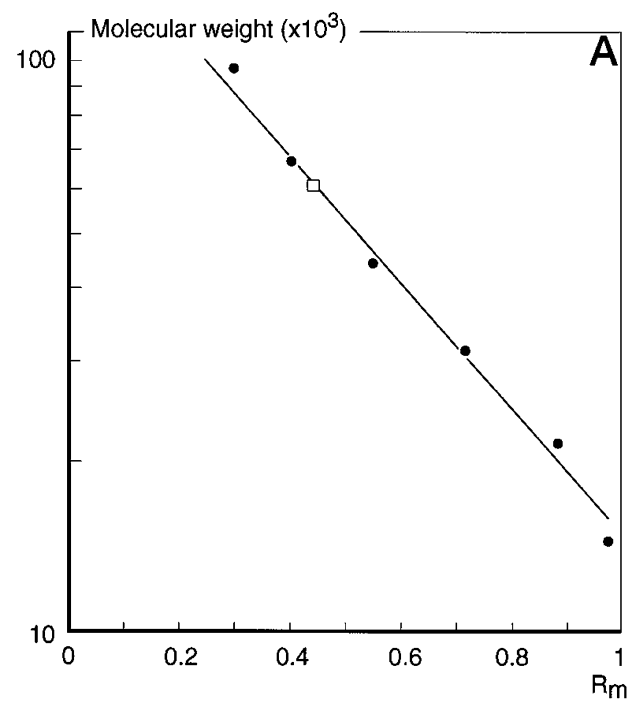

period, but the rate of the HS-CoM conversion was $64 \%$ of the rate obtained with $2 \mathrm{~mm}$ ATP. UV illumination of partly purified MAP in the presence of 8-azido-ATP resulted in a clear retardation of the reaction with respect to MAP controls that had been preincubated in the dark with the ATP analogue or MAP that had been exposed to UV light in the absence of 8-azido-ATP (Fig. 3). These same treatments of either $\mathrm{MT}_{1}$ or $\mathrm{MT}_{2}$ /hydrogenase fractions had no effect on the methyltransferase activities (data not shown). Since ferredoxin was not absolutely required for methyl group transfer (10), the electron carrier was not specifically tested for the effect of 8-azido-ATP and UV illumination. The inhibition by 8 -azido-ATP and UV light treatment was confirmed with purified MAP.

Preincubations with ATP-The effect of 8-azido-ATP suggested that the role of ATP was linked to MAP. This was substantiated by an experiment in which MAP was preincubated with ATP (Fig. 4). Subsequent removal of excess ATP followed by assay in the further absence of ATP showed that MAP preincubated with ATP could substitute for the requirement of ATP. No activity was found when the ATP preincubation was performed with the combined $\mathrm{MT}_{1}$ and $\mathrm{MT}_{2} / \mathrm{hy}-$ drogenase fractions. Controls in which glucose/hexokinase/ myokinase-treated ATP was added to the preincubations or to the assays also did not show any activity, demonstrating that the compound was effectively removed.

When the methanol:HS-CoM methyltransfer reaction was assayed in the absence of ATP with increasing amounts of MAP preincubated with ATP, reaction rates increased correspondingly and no lag period was observed (Fig. 5A). This suggests that ATP-preincubated MAP stoichiometrically interacts with $\mathrm{MT}_{1}$ during the activation. If the assays were performed with the same increasing amounts of MAP in the presence of ATP (2 $\mathrm{mM}$ ), similar maximal reaction rates were obtained after certain lag phases (Fig. 5B). The lag phases tended to increase the lower the amount of MAP applied. Apparently, substoichiometric amounts of MAP may quantitatively activate $\mathrm{MT}_{1}$ provided sufficient ATP is present.

ATP Conversion-The experiments outlined above unequivocally showed that MAP was the immmediate site of action of ATP. In agreement with this observation, partially purified MAP obtained after DEAE-Sepharose chromatography was able to react with ATP, as determined by a luciferine/luciferase assay. The activity coincided with MAP during the subsequent

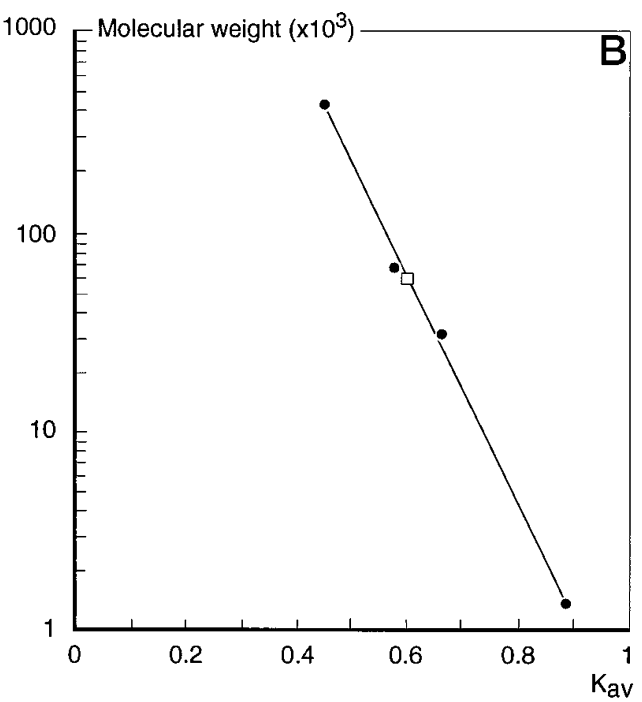

FIG. 2. Estimation of the molecular weight of native and SDS-treated MAP. A, SDS-treated MAP ( $\square$ ) and markers (๑) were applied to a 10-15\% gradient Phastgel. The standards and their molecular weights are given under "Experimental Procedures." $B$, the native molecular weight of MAP $(\square)$ was determined by Superose-6 gel filtration chromatography as described under "Experimental Procedures." The markers $(\bullet)$ and their molecular weights are given under "Experimental Procedures." $K_{\mathrm{av}}$, distribution coefficient. 


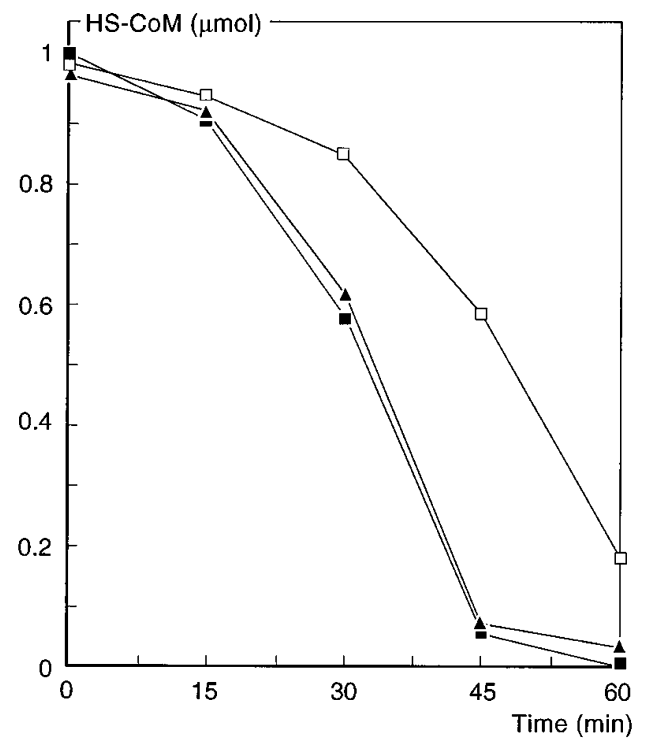

FIG. 3. Effect of 8-azido-ATP and UV illumination on the activity of MAP. Reaction mixtures (final volume, $100 \mu \mathrm{l}$ ) contained $50 \mathrm{~mm}$ TES/K $\mathrm{K}^{+}, 24 \mathrm{~mm} \mathrm{MgCl}_{2}, 10 \mathrm{~mm}$ methanol, $10 \mathrm{~mm}$ HS-CoM, $2 \mathrm{~mm}$ ATP, 1 $\mathrm{mM}$ 2-bromoethanesulfonic acid, $20 \mu \mathrm{l}$ of $\mathrm{MT}_{2} /$ hydrogenase fraction, $12.5 \mu \mathrm{l}$ of $\mathrm{MT}_{1}$ fraction, $10 \mu \mathrm{l}$ of ferredoxin fraction, and $20 \mu \mathrm{l}$ of treated DEAE-Sepharose fraction of MAP. Incubations were performed under $50 \% \mathrm{H}_{2} / 50 \% \mathrm{~N}_{2}$ at $37^{\circ} \mathrm{C}$. Assay with MAP after incubation with 8-azido-ATP and UV illumination for $1 \mathrm{~h}(\square)$. The control experiments contained MAP illuminated in the absence of 8-azido-ATP (ם) and MAP incubated with 8-azido-ATP in the dark ( $\mathbf{\Lambda})$.

purification steps. Anaerobic incubation of purified MAP with $\left[8-{ }^{14} \mathrm{C}\right] \mathrm{ATP}$ and subsequent thin-layer chromatography and autoradiography of the reaction mixture demonstrated that ATP was converted into ADP (Fig. 6). Time course experiments with varied amounts of MAP showed $\left[8-{ }^{14} \mathrm{C}\right] \mathrm{ADP}$ to be produced at an initial rate of at least $1 \mathrm{nmol} \mathrm{min}{ }^{-1} \mathrm{mg}$ of protein ${ }^{-1}$ (Fig. 7). However, the reactions came to an end when $1.0 \pm 0.3$ mol of $\left[{ }^{14} \mathrm{C}\right] \mathrm{ADP}$ was formed per mol of MAP added, suggesting that the reaction was stoichiometric rather than catalytic. The amount of ATP converted to ADP was not increased by using higher concentrations of ATP (up to $0.5 \mathrm{~mm}$ tested). The addition of methanol had no effect on the rate of hydrolysis or on the final amount of ADP produced, which ruled out the possibility that MAP catalyzed the formation of the putative activating substance, methyl-phosphate. The effect of $\mathrm{MT}_{1}$ on the reaction of MAP with ATP was tested. The presence of $\mathrm{MT}_{1}$, however, interfered with the work-up and subsequent TLC analyses of the reaction mixtures such that $\left[{ }^{14} \mathrm{C}\right] \mathrm{ATP}$ and $\left[{ }^{14} \mathrm{C}\right] \mathrm{ADP}$ were only partly resolved and the latter could not be accurately measured. The reaction of MAP with ATP was remarkably stable. Aerobic incubations of MAP with $\left[{ }^{14} \mathrm{C}\right] \mathrm{ATP}$ did not result in a significant decrease in the amount of ATP converted. When MAP was kept under air for $3 \mathrm{~h}$, a $23 \%$ decrease in the extent of ATP conversion was observed. Only a $12 \%$ decrease was obtained when MAP was anaerobically heated for $30 \mathrm{~min}$ at $100{ }^{\circ} \mathrm{C}$. It should be noted that these same treatments resulted in complete inactivation of MAP in the methyltransferase assay.

Phosphorylation of MAP-Upon incubation of MAP with $\left[8-{ }^{14} \mathrm{C}\right] \mathrm{ATP}$ followed by washing the reaction mixtures on Ultrafree-MC filter units, all radioactivity was recovered in the eluate. In contrast, when the same experiment was performed with $\left[\gamma_{-}{ }^{32} \mathrm{P}\right] \mathrm{ATP}$ radioactivity remained associated with the protein that was retained by the filter. In addition, label consistently coprecipitated with $\left[\gamma_{-}{ }^{32} \mathrm{P}\right] \mathrm{ATP}$-incubated MAP after addition of $20 \%$ trichloroacetic acid to the reaction mixtures and subsequent washing steps with trichloroacetic acid. Quan-

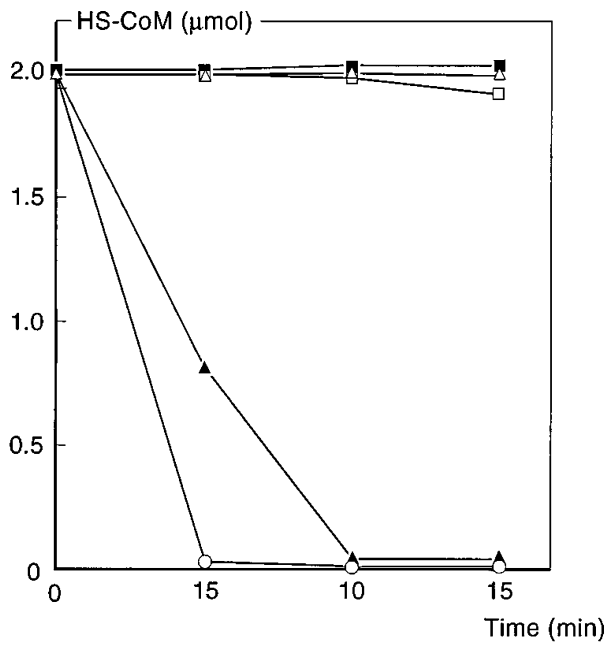

FIG. 4. Effect of ATP and preincubation with ATP on the methanol:HS-CoM methyltransferase reaction. The reaction mixtures (final volume, $200 \mu \mathrm{l}$ ) contained $50 \mathrm{~mm} \mathrm{TES} / \mathrm{K}^{+}$buffer $(\mathrm{pH} 7.0), 24 \mathrm{~mm}$ $\mathrm{MgCl}_{2}, 10 \mathrm{~mm}$ methanol, $10 \mathrm{~mm}$ HS-CoM, $1 \mathrm{~mm}$ 2-bromoethanesulfonic acid, $25 \mu \mathrm{l}$ of $\mathrm{MT}_{1}$ fraction, $35 \mu \mathrm{l}$ of $\mathrm{MT}_{2} /$ hydrogenase fraction, $70 \mu \mathrm{l}$ of MAP fraction, $35 \mu \mathrm{l}$ of ferredoxin fraction, and ATP as specified hereafter. The results of the following experiments are shown: complete assay containing $2 \mathrm{~mm}$ ATP $(\mathrm{O})$, complete assay containing $2 \mathrm{~mm}$ glucose/hexokinase/myokinase-treated ATP (ष), assay containing $2 \mathrm{~mm}$ ATP and omitting MAP fraction $(\triangle)$, assay containing ATP-preincubated $\mathrm{MT}_{1}(25 \mu \mathrm{l})$ plus $\mathrm{MT}_{2}$ /hydrogenase $(35 \mu \mathrm{l})$ fractions and omitting ATP $(\square)$, and assay containing ATP-preincubated MAP fraction $(70 \mu \mathrm{l})$ and omitting ATP $(\boldsymbol{\Lambda})$. The enzyme fractions were obtained by DEAESepharose chromatography of cell extract. Incubations took place under $50 \% \mathrm{H}_{2}, 50 \% \mathrm{~N}_{2}$ at $37^{\circ} \mathrm{C}$. Preincubations and glucose/hexokinase/ myokinase treatments were carried out as described under "Experimental Procedures."

tification of the labeling showed that is was bound to the protein in a 1:1 stoichiometry with respect to MAP. From these experiments it was concluded that MAP was phosphorylated by the $\gamma$-phosphoryl group of ATP. Protein phosphorylation was also verified by polyacrylamide gel electrophoresis of MAP that had been incubated with $\left[\gamma_{-}{ }^{32} \mathrm{P}\right] \mathrm{ATP}$. After native $8-25 \%$ PAGE, clearly labeled bands were observed with apparent molecular masses of $61,000,120,000$, and higher (Fig. 8), indicative of mono-, di-, and oligomer forms of ${ }^{32}$ P-labeled MAP. SDS sample preparation at elevated temperatures and subsequent SDS-PAGE demonstrated the presence of ${ }^{32} \mathrm{P}_{\mathrm{i}}$ in a band with a molecular weight of 60,000 and in an indistinct region around $M_{\mathrm{r}}=27,000$ (data not shown). These radioactive bands were also observed after mild treatment with SDS at ambient temperature by the procedure that yielded only one $60-\mathrm{kDa}$ band for the purified protein (Fig. 1). This points to an increased instability of phosphorylated MAP toward SDS treatment. Stability tests as described by Martensen (14) demonstrated the ${ }^{32} \mathrm{P}$-protein linkage to be acid-stable. Phosphorylation was also observed, when the reactions were performed under aerobic conditions.

\section{DISCUSSION}

In $M$. barkeri, transfer of the methyl group of methanol to HS-CoM proceeds via the oxidation-sensitive corrinoid protein $\mathrm{MT}_{1}$ (7). Inactive $\mathrm{MT}_{1}$ may be reactivated by the combined action of a reducing system $\left(\mathrm{H}_{2}\right.$, hydrogenase, ferredoxin), ATP, and a previously unresolved protein fraction called MAP (810). From the data presented here, it is clear that the effect of the MAP fraction on the activation of $\mathrm{MT}_{1}$ is the result of the action of a single protein present in that fraction. MAP was isolated as a protein with a molecular weight of 60,000 . The enzyme appeared to be an aerobically unstable, difficult to handle protein that was difficult to resolve from other proteins 

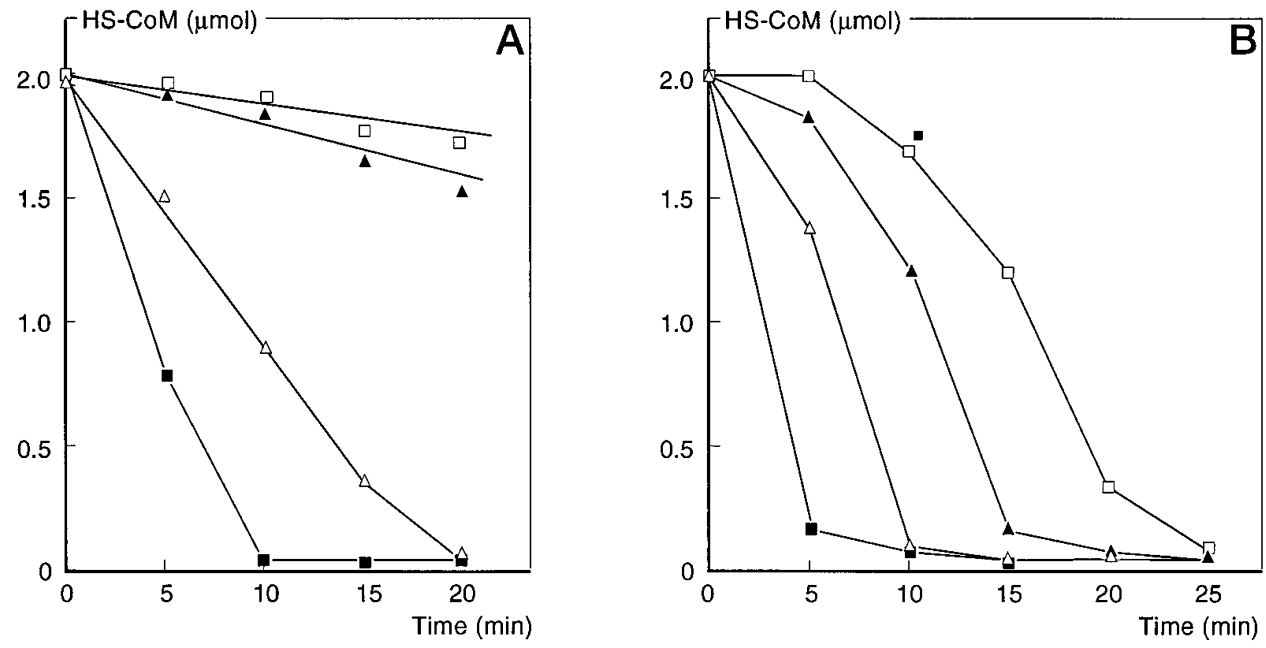

FIG. 5. Effect of various amounts of MAP on the methanol:HS-CoM methyltransferase reaction. The reactions were performed as described in Fig. 2 in the absence $(A)$ or presence $(B)$ of $2 \mathrm{~mm} \mathrm{ATP}$ and $7 \mu \mathrm{l}(\square), 15 \mu \mathrm{l}(\mathbf{\Delta}), 35 \mu \mathrm{l}(\triangle)$, or $70 \mu \mathrm{l}(\mathbf{\square})$ of MAP fraction. In $A$, ATP-preincubated MAP was added; preincubation and subsequent trapping of excess ATP were carried out as specified under "Experimental Procedures."

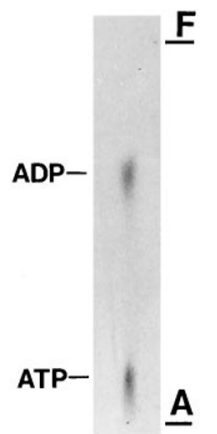

FIG. 6. Reaction of MAP with ATP to give ADP. An autoradiogram of a thin-layer chromatogram used to separate $\left[8-{ }^{14} \mathrm{C}\right] \mathrm{ATP}$ and $\left[8-{ }^{14} \mathrm{C}\right] \mathrm{ADP}$ is shown. The reaction mixture $(100 \mu \mathrm{l})$ contained $50 \mathrm{mM}$ TES/K ${ }^{+}$buffer (pH 7.0), $2 \mu \mathrm{M} \mathrm{MgCl}_{2}, 2 \mu \mathrm{M}\left[8^{-14} \mathrm{C}\right] \mathrm{ATP}$, and $40 \mu \mathrm{l}$ of 79 -fold purified MAP (3.06 $\mu \mathrm{g}$ of protein) and was incubated for $2 \mathrm{~h}$ under $50 \% \mathrm{H}_{2}, 50 \% \mathrm{~N}_{2}$ at $37{ }^{\circ} \mathrm{C}$. Sampling and chromatography was as described under "Experimental Procedures." A, application line; $F$, solvent front.

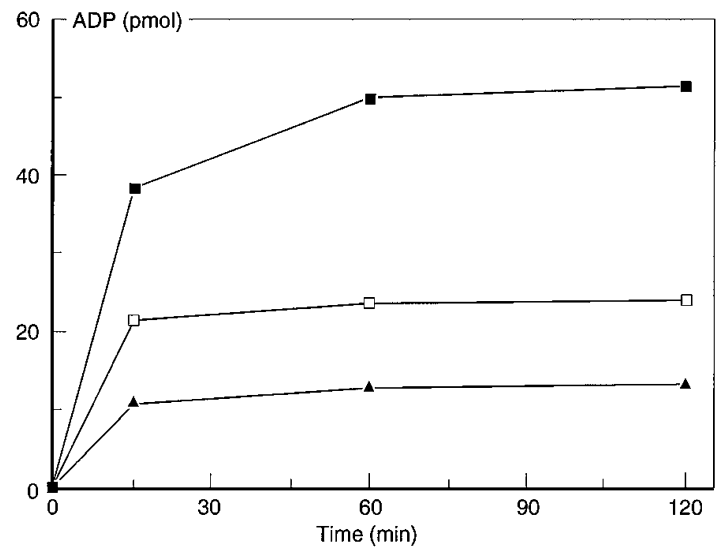

FIG. 7. Time course of ADP formation in the reaction of ATP with various amounts of MAP. Reactions were performed as described for Fig. 6, except that the amount of MAP was varied. Addition of $10 \mu \mathrm{l}(\mathbf{\Lambda}), 20 \mu \mathrm{l}(\square)$, and $40 \mu \mathrm{l}(\mathbf{\square})$ of MAP corresponded with 12.8, 25.5 , and $51.1 \mathrm{pmol}$ of the protein, respectively. Sampling and quantification of $\left[8-{ }^{14} \mathrm{C}\right] \mathrm{ADP}$ was as described under "Experimental Procedures."

unless the zwitterionic detergent CHAPS was added to the chromatography buffers.

The inhibitory effect of 8-azido-ATP and UV illumination

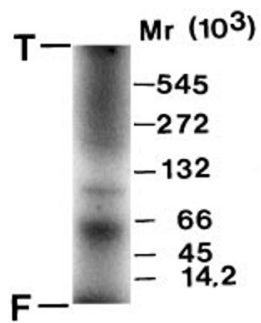

FIg. 8. Phosphorylation of MAP by $\left[\gamma_{-}{ }^{32} \mathbf{P}\right]$ ATP. An autoradiogram of a nondenaturing PAGE is shown. Incubation was for $2 \mathrm{~h}$ under air at $37^{\circ} \mathrm{C}$. A $4-\mu \mathrm{l}$ sample $(0.13 \mu \mathrm{g}$ of protein) was applied to a $8-25 \%$ gradient Phastgel. The reaction mixture was as described under "Experimental Procedures." The numbers at the right side refer to the molecular masses $(\mathrm{kDa})$ of the protein standards. $T$, top; $F$, front.

(Fig. 3), the preincubation studies with ATP (Figs. 4 and 5), and the reaction with $\left[8-{ }^{14} \mathrm{C}\right] \mathrm{ATP}$ (Figs. 6 and 7 ) clearly indicate that MAP is the direct site of action of ATP in the activation of $\mathrm{MT}_{1}$. In fact, MAP was autophosphorylated by the $\gamma$-phosphoryl group of ATP. This is the first example of a phosphorylated protein in methanogenic archaea. The acid stability of the phosphate bond suggests an $O$-phosphate linkage (14). Whereas the action of the protein in the activation of $\mathrm{MT}_{1}$ was destroyed upon exposure to air or high temperature, the autophosphorylating activity of MAP was quite resistant toward these treatments. SDS-PAGE performed under mild conditions revealed the presence in the purified protein of a single $59-\mathrm{kDa}$ band (Fig. 1). This band remained detectable after heating in SDS sample buffer, but an ill-defined region around $30 \mathrm{kDa}$ was stained as well. SDS-PAGE of ${ }^{32} \mathrm{P}$-labeled MAP showed radioactivity to be associated with a $27-\mathrm{kDa}$ band, which was not observed after electrophoresis under nondenaturing conditions (Fig. 8). Although SDS-PAGE did not permit a resolution into clearly distinct bands, this could suggest that MAP is a (hetero)dimeric protein and that the autophosphorylating activity is associated with a $27-\mathrm{kDa}$ component.

The activation of $\mathrm{MT}_{1}$ is strictly dependent on MAP and ATP (this paper; Ref. 10). Since MAP is phosphorylated by ATP and since ATP-preincubated MAP substitutes for ATP, it is evident that MAP-phosphate is the actual effector in the activation process. Addition of increasing amounts of MAP-phosphate resulted in a corresponding increase of active $\mathrm{MT}_{1}$ (Fig. $5 \mathrm{~A}$ ), indicating that MAP-phosphate stoichiometrically interacts with $\mathrm{MT}_{1}$ during the activation, which we have confirmed by 
EPR experiments (19). However, limiting amounts of MAP may quantitatively activate $\mathrm{MT}_{1}$ in the course of a lag phase if ATP is present. This may be explained by assuming that MAPphosphate becomes dephosporylated during the activation of an $\mathrm{MT}_{1}$ molecule and after rephosphorylation by ATP MAPphosphate can activate another $\mathrm{MT}_{1}$. It should be noted that MAP is isolated in the unphosphorylated state, supporting the view that phosporylation and dephosphorylation would play a role in the activation mechanism. With respect to the role of MAP-phosphate two modes of action now may be envisaged. (i) The phosphate group is transferred to $\mathrm{MT}_{1}$, changing the structure of the latter protein and/or its corrinoid prosthetic group in a way that reductive activation is facilitated. In this respect MAP acts like a protein kinase (16). (ii) Without covalently altering $\mathrm{MT}_{1}$, MAP-phosphate affects the structure of the protein and/or its corrinoid prosthetic group. Here, the function of MAP-phosphate resembles the action of chaperone proteins (17). In both mechanisms, the coordination of the 5-hydroxybenzimidazolyl ligand of the corrinoid prosthetic group of $\mathrm{MT}_{1}$ is eventually modified to an extent that the thermodynamically unfavorable reduction of $\mathrm{Co}$ (II) to $\mathrm{Co}$ (I) becomes accessible for hydrogen/hydrogenase and the concomitant methylation by methanol $(18,19)$.
REFERENCES

1. Banerjee, R. V., and Matthews, R. G. (1990) FASEB J. 4, 1450-1459

2. Keltjens, J. T., and van der Drift, C. (1986) FEMS Microbiol. Rev. 39, 259-303

3. Matthews, R. G., Banerjee, R. V., and Ragsdale, S. W. (1990) Biofactors 2, $147-152$

4. Stupperich, E. (1993) FEMS Microbiol. Rev. 12, 349-366

5. Banerjee, R. V., Harder, S. R., Ragsdale, S. W., and Matthews, R. G. (1990) Biochemistry 29, 1129-1135

6. van der Meijden, P., Heythuysen, H. J., Pouwels, A., Houwen, F., van der Drift, C., and Vogels, G. D. (1983) Arch. Microbiol. 134, 238-242

7. van der Meijden, P., te Brömmelstroet, B. W., Poirot, C. M., van der Drift, C., and Vogels, G. D. (1984) J. Bacteriol. 160, 629-635

8. van der Meijden, P., van der Lest, C., van der Drift, C., and Vogels, G. D. (1984) Biochem. Biophys. Res. Commun. 118, 760-766

9. van der Meijden, P., Heythuysen, H. J., Sliepenbeek, H. T., Houwen, F. P., van der Drift, C., and Vogels, G. D. (1983) J. Bacteriol. 153, 6-11

10. Daas, P. J. H., Gerrits, K. A. A., Keltjens, J. T., van der Drift, C., and Vogels, G. D. (1993) J. Bacteriol. 175, 1278-1283

11. Hutten, T. J., De Jong, M. H., Peeters, B. P. H., van der Drift, C., and Vogels, G. D. (1981) J. Bacteriol. 145, 27-34

12. Stahl, E. (1967) Dünnschicht-Chromatographie: Ein Laboratoriumshandbuch, 2nd Ed., Springer Verlag, Berlin

13. Ellman, G. L. (1958) Arch. Biochem. Biophys. 74, 443-450

14. Martensen, T. M. (1984) Methods Enzymol. 107, 3-23

15. Chuan, H., Lin, J., and Wang, J. H. (1989) J. Biol. Chem. 264, 7981-7988

16. Cozzone, A. J. (1993) J. Cell. Biochem. 51, 7-13

17. Hendrick, J. P., and Hartl, F.-U. (1993) Annu. Rev. Biochem. 62, 349-384

18. Daas, P. J. H., Keltjens, J. T., Hagen, W. R., and van der Drift, C. (1995) Arch. Biochem. Biophys. 319, 244-249

19. Daas, P. J. H., Hagen, W. R., Keltjens, J. T., van der Drift, C., and Vogels, G. D. (1996) J. Biol. Chem. 271, 22346-22351 